\title{
Vitamin B12 Replasman Tedavisi; Oral? İntramüsküler?
}

\section{Vitamin B12 Replacement Treatment; Oral? Intramuscular?}

\author{
Maruf BORAN_.1 1 , Ömer Faruk BORAN $2{ }^{\mathbb{D}}$, Nisbet YILMAZ ${ }^{3} \mathbb{D}$, Başol CANBAKAN 4
}

\begin{abstract}
1 Amasya Üniversitesi Sabuncuoğlu Şerefeddin EAH Genel Yoğun Bakım Servisi, Amasya,Türkiye
2 Kahramanmaraş Sütçü Imam Üniversitesi Tıp Fakültesi Anesteziyoloji ve Reanimasyon ABD, Kahramanmaraş, Türkiye

3 Ankara Şehir Hastanesi l̇ç Hastalıkları Kliniği Ankara, Türkiye

4 Kars Kafkas Üniversitesi Tıp Fakültesi İç Hastalıkları Anabilim Dalı, Kars, Türkiye
\end{abstract}

Öz.

Amaç: Bu çalışmanın amacı intramüsküler B12 replasman tedavisi ile oral B12 replasman tedavisinin kan B12 vitamini düzeyleri üzerine olan etkisinin karşılaştııımasıdır.

Materyal ve Metod: Çalışma Ankara Numune Eğitim Araştırma Hastanesi (EAH) Bilimsel Araştırmalar Değerlendirme Komisyonunun 24/07/2013 tarih ve 2013-646 saylı kararı ile yapıımışıı. Ankara Numune EAH 3 Dahiliye polikliniğine MayısEkim 2012 tarihleri arasında başvuran ve yeni tanı B12 vitamini eksikliği saptanan, oral veya intramüsküler tedavi başlanan, bir ay sonra kontrole gelen hastalar retrospektif taranarak çalışmaya alınmıştır. İstatistiksel analizler "SPSS for Windows 20,0" paket programı ile yapılmışıı.

Bulgular: Oral vitamin B12 replasman tedavisi alan 56, intramüsküler vitamin B12 replasman tedavisi alan 46 hasta bulundu.

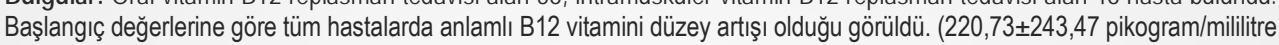
$(\mathrm{pg} / \mathrm{ml}), \mathrm{p}<0,001)$. Oral tedavi alanlarda B12 vitamini artıș $252,91 \pm 297,23 \mathrm{pg} / \mathrm{ml}$, intramüsküler tedavi alanlarda B12 vitamini artışı 182,96 $\pm 152,90 \mathrm{pg} / \mathrm{ml}$ olarak saptandı. Oral ve intramüsküler tedavi alan hastaların B12 vitamini düzey arıışları arasında fark tespit edilmedi $(p>0,05)$.

Sonuç: Oral ve intramüsküler B12 replasman tedavi kollarına ayrılarak yapılan bir çalıșmada 90 günlük tedavi sonrasında oral ve intramüsküler tedavi ile B12 vitamini düzeyinde artış olduğu bulunmuş ancak gruplar etkinlik açısından karşıllaştıııımamıştır. Bizim çalışmamızda B12 vitamini eksikliği saptanan hastalarda oral ve intramüsküler B12 replasman tedavileri arasında fark saptanmamış olması, oral replasman tedavisinin intramüsküler tedaviye alternatif olabileceğini akla getirmektedir. Konu ile ilgili yeni, daha geniş kapsamlı randomize kontrollü çalışmalara intiyaç olduğu ortadadır.

Anahtar Kelimeler: Oral, İntramüsküler, Vitamin B12, Replasman

Abstract

Background: Vitamin B12 deficiency is one of the common diseases in the community which can cause hematological and neurological symptoms and signs. It is usually treated by intramuscular injection after diagnosis. The aim of this study was to compare oral and intramuscular B12 replacement therapy.

Materials and Methods: The study was started with the decision dated 24/07/2013 and numbered 2013-646 of the Scientific Research Evaluation Commission of Ankara Numune Training and Research Hospital. Patients who were admitted to the internal medicine outpatient clinic between May-October 2012 and whom were recently diagnosed with vitamin B12 deficiency, that received oral or intramuscular therapy, and came to the control one month later, were included in the study. Statistical analysis was performed with "SPSS for Windows 20.0" SS package program.

Results: 56 patients with oral vitamin B12 replacement therapy and 46 patients with intramuscular vitamin B12 replacement therapy were found. According to baseline values, significant increase in vitamin B12 levels was observed in all patients. (220.73 $\pm 243.47 \mathrm{pg} / \mathrm{ml}, \mathrm{p}<0.001)$. Vitamin B12 increase was $252,91 \pm 297,23 \mathrm{pg} / \mathrm{ml}$ in oral treatment group and $182,96 \pm 152,90$ $\mathrm{pg} / \mathrm{ml}$ in intramuscular treatment group respectively. There were no significant differences between two groups $(\mathrm{p}>0.05)$. Conclusion: In a study that was divided into oral and intramuscular B12 replacement therapy, an increase in vitamin B12 levels was found with oral and intramuscular treatment after 90 days of treatment, but the groups were not compared in terms of efficacy. In our study, since there was no difference between oral and intramuscular B12 replacement therapies in patients with vitamin B12 deficiency, may suggest that oral replacement therapy may be an alternative to intramuscular therapy. Further comprehensive randomized controlled studies are required to determine the efficiency of intramuscular B12 replacement therapy.

Key words: Oral, Intramuscular, Vitamin B12, Replacement

\section{Sorumlu Yazar I Corresponding Author}

Dr Maruf Boran

Amasya Üniversitesi

Sabuncuoğlu Şerafeddin Eğitim Araştırma Hastanesi

Genel Yoğun Bakım Servisi

Kirazlıdere Mahallesi Turgut Özal

Caddesi

05200 Amasya

Tel: 05064720087

e-mail: marufboran@gmail.com

Geliş tarihi / Received:

02.10.2019

Kabul tarihi / Accepted:

21.02.2020

\section{DOI: $10.35440 /$ hutfd. 628409}

\section{*24-27 Nisan 2019 tarihlerinde Burdur Mehmet Akif Ersoy \\ Üniversitesi tarafından düzenlenen 2. Uluslararası Sağılk Bilimleri ve Yaşam Kongresinde sözlü sunu olarak sunulmuştur.}

\section{${ }^{*} B u$ çalışma Dr. Maruf Boran'ın tıpta uzmanlık tezinden üretilmiştir}




\section{Giriş}

B12 vitamini DNA sentezinde ve hücre bölünmesinde etkin rol alan bir vitamindir. Hücre içerisinde deoksiribonükleik asit sentezinde kofaktör olarak görev almaktadır (1,2). Propiyonil koenzim $A$ süksinil koenzim $A$ dönüşümünde rol alır ki bu dönüşümün özellikle myelin sentezinde önemli olduğu düşünülmektedir (3). Günlük B12 vitamini ihtiyacı 14 mikrogramdır ve gereksinimi hayvansal gıdalar ile karşılanabilmektedir (1,2). Değişik dokularda 1 -2 miligram kadar depolanabilen B12 vitamininin asıl depolanma yeri karaciğer olup, yaklaşık 4 yıllık B12 vitamini intiyacını karşılayabilmektedir (4).

B12 vitamini eksikliği prevelansının yaş ile birlikte arttığı ve sıklığının \%15-40 aralığında değişik oranlarda olduğu bildirilmektedir (5). Sessiz ve polimorfik kliniğinden dolayı B12 eksikliği tanısı koymak zor olabilmektedir $(6,7)$. Eksikliğinde hastalarda OEV (Ortalama Eritrosit Volümü) yüksekliği ile seyreden anemi, periferik yaymada hipersegmente nötrofiller, pansitopeni gibi hematolojik bozukluklar ortaya çıkabilmektedir (8-10). Nörolojik olarak davranış bozuklukları, halsizlik, ataksi, parestezi gibi semptom ve bulgular ile seyredebilen klinik tablo ortaya çıkabilmektedir $(7,8)$. Eksiklik durumunda ilk önce nörolojik bulgular ortaya çıkarken anemi gelişimi 3 yılı bulabilmektedir $(10,11)$. B12 vitamininin emiliminin gerçekleşmesi için diyet ile yeterli miktar alınması, mide asit ve pepsini ile proteinlerden serbestlenmesi, mide paryetal hücrelerinden salgılanan intrinsik faktör ile birleşmesi ve sağlam bir terminal ileum varlığı gerekmektedir (12-14). Emilen B12 vitamini transkobalamin II ile kanda taşınır ve hücrelere reseptör aracılı endositoz yolu ile alınır (15).

B12 vitamini eksikliği pernisyöz anemi, kronik atrofik gastrit, mide cerrahisi geçirme gibi gastrik bozukluklarda, kör bağırsak ansı, ileum rezeksiyonu, çölyak hastalığı gibi intestinal bozukluklarda, katı vejeteran beslenmede, metformin, proton pompa inhibitörleri gibi ilaçların kullanımı sonrasında gelişebilmektedir (16-18).

Sadece B12 vitamini düzeyine bakılarak eksiklik teşhisi koymak zor olabilmektedir $(15,16)$. Yapılan çalışmaların sonuçlarına göre $200 \mathrm{pg} / \mathrm{ml}$ değerinin altı eksiklik olarak kabul görmektedir (16-18). 200-300 pg/ml arası değerler şüpheli olarak adlandırımakta ve klinik şüphe varlığında homosistein ve metil malonik asit düzeylerine bakmak faydalı olabilmektedir (18). 300 pg/ml üzerindeki değerlerde çok ciddi klinik şüphe varsa metabolitlerin bakılması önerilmektedir (17). Metabolit düzeylerininde birçok hastalık ve durumda değişiklik gösterebildiği göz önünde bulundurulmalı $(16,19)$ ve şüpheli değerler tekrarlanmalıdır $(17,20)$.

Hastaların laboratuar değerlerine bakıldığında inefektif eritropoeze bağlı demir yüksekliği, indirekt bilirubin ve laktik dehidrojenaz düzeylerinde artma, haptoglobin düzeyinde azalma, periferik yaymada makroovalositler, hipersegmente nötrofiller görülürken, serum homosistein düzeyinde artış görülebilmektedir.
Türk Hematoloji Derneği'nin 2011 yılında yayınlanan B12 Eksikliği Kılavuzunda eksiklik saptanması durumunda oral veya intramüsklüler tedavinin başlanması ve daha sonra etyolojik sebebi araştıııması önerilmektedir (21). İntramüsküler enjeksiyon yolu ile B12 vitamini replasmanının yapıması günümüzde klasik tedavi yöntemi haline gelmiştir (18). Tedavi rejimi değişiklik göstermekle beraber ilk hafta hergün $1000 \mu \mathrm{g}$ (mikrogram), daha sonra 4 hafta süre ile haftada bir kez $1000 \mu \mathrm{g}$ ve daha sonra eksikliğin sebebi ortadan kaldırılamıyor ise ayda bir kez $1000 \mu \mathrm{g}$ B12 vitamini replasmanının ömür boyu yapılması önerilmektedir (21). Intramüsküler enjeksiyon ile replasman tedavisinde hastalar bir sağlık kuruluşuna başvurmak zorunda kalmakta ve intramüsküler enjeksiyonun riskleri ile karşılaşmaktadırlar $(17,18)$. Değişik sebeplerden dolayı hastalar intramüsküler tedavi uygulanabilecek merkeze ulaşımda zorluk yaşayabilmekte, bu durum tedavinin yapılmamasına veya eksik bırakılmasına sebep olabilmektedir (17). Bu sebeplerden ötürü intramuskuler yol dışında kullanılabilen, oral veya nazal replasman tedavisi gündeme gelmektedir (22).

Bu çalışmanın amacı oral yoldan verilen B12 vitamini replasmanının intramüsküler yol ile yapılan replasman kadar etkin olup olmadığını belirlemektir. Ayrıca çalışmaya alınan hastaların demografik özellikleri, saptanabilen B12 vitamini eksikliği risk faktörleri tanımlanacaktır.

\section{Materyal ve Metod \\ Araştırmanın yeri ve katıımcıların özellikleri}

Çalışma, Ankara Numune Eğitim Araştırma Hastanesi (ANEAH) Bilimsel Araştırmalar Değerlendirme Komisyonunun 24/07/2013 tarih ve 2013 - 646 sayll kararı ile yapılmaya başlandı. ANEAH 3. Dahiliye polikliniğine MayısEkim 2012 tarihleri arasında başvuran ve herhangi bir sebeple bakılan B12 vitamini düzeyi 50-193 pg/ml aralığında saptanan hastalar hastane otomasyon sistemi üzerinden retrospektif olarak tarandı. B12 vitamini düzeyi belirtilen aralıkta olan ve oral veya intramüsküler replasman başlanan ve 1 ay sonra kontrole gelen hastalar yaş, cinsiyet, kronik hastalık ve ilaç kullanım ayrımı olmadan çalışmaya alındı.

İlk başvuruda B12 replasmanı alan hastalar, ciddi nörolojik yakınması olanlar (dorsal kök tutulumuna bağlı duyu kusuru vb.), eşlik eden folik asit düzey düşüklüğünün var olması, malabsorbsiyona sebep olan hastalık/durum varlığı (jejunum/ileum rezeksiyonu, Çölyak hastalığı vb) B12 vitamini replasmanına hipersensitivite olması, hemofili veya benzeri kanama diyatezine sebep olan hastalıkların varlığı veya kontrolde hastanın tedaviyi düzenli almadığını belirtmesi durumunda çalışmadan dışlanmışlardır. Kriterlere uyan toplam 102 hasta taranmıştır. Hastaların 56 tanesi oral B12 replasman tedavisi alırken 46 tanesi intramüsküler B12 replasman tedavisi almakta idi. 


\section{Prosedür}

Hastaların yaş, cinsiyet, kronik hastalıkları, kullandıkları ilaçlar, ilk başvuruda bakılan beyaz küre sayısı, hemoglobin düzeyi, ortalama eritrosit volümü, platelet sayısı, laktik dehidrojenaz enzim düzeyi, folik asit ve B12 vitamini düzeyleri ile 1 ay sonra bakılan beyaz küre sayısı, hemoglobin düzeyi, ortalama eritrosit volümü, platelet sayısı, laktik dehidrojenaz enzim düzeyi ve B12 vitamini düzeyleri kaydedildi.

\section{Verilerin değerlendirilmesi}

Vaka verileri değerlendirilirken "SPSS for Windows 20,0" paket programı kullanıldı. Verilerin standart sapma ve ortama değerleri belirlendi. $p<0,05$ olması anlamlılık kabul edildi. Mann-Whitney U testi, Pearson Korelasyon Analizi ve ki-kare testi uygulandı.

\section{Bulgular}

Çalışmaya alınan hastaların 69'u kadın, 39'u erkeklerden oluşmaktaydı. Yaş ortalaması $47 \pm 15,26$ olarak bulundu. Grupların yaş ve cinsiyet dağılımları Tablo 1'de gösterilmektedir. Çalışmaya alınan hastaların kronik hastalık dağılımları tablo 2'de gösterilmektedir. B12 vitamini eksikliği yapan ilaç kullanımına bakıldığında metformin 22 vaka tarafından proton pompa inhibitörü ise 12 hasta tarafından kullanılmakta idi. Oral tedavi kolunda 13 hasta metformin, 6 hasta proton pompa inhibiörü kullanmakta iken intramüsküler tedavi kullanan hastaların 9 tanesi metformin ve 6 hasta proton pompa inhibitörü kullanmakta idi.

Tablo 1. Grupların yaş ve cinsiyet dağı̆ımlarının karşılaştııılması

\begin{tabular}{lllll}
\hline & $\begin{array}{l}\text { Tüm } \\
\text { vakalar } \\
(\mathrm{n}=102)\end{array}$ & $\begin{array}{l}\text { Oral tedavi } \\
\text { grubu } \\
(\mathrm{n}=56)\end{array}$ & $\begin{array}{l}\text { İntramüsküler } \\
\text { tedavi grubu } \\
(\mathrm{n}=46)\end{array}$ & $\begin{array}{l}\mathbf{P} \\
\text { değeri }\end{array}$ \\
\hline Yaş & $47,6 \pm 15,26$ & $47,53 \pm 13,39$ & $47,53 \pm 16,76$ & $>0,05$ \\
\hline $\begin{array}{l}\text { Cinsiyet } \\
\text { (kadın / } \\
\text { erkek) }\end{array}$ & $63 / 39$ & $33 / 23$ & $30 / 16$ & $>0,05$ \\
\hline
\end{tabular}

Çalışmaya alınan hastaların ortalama B12 vitamini düzeyi $154,88 \pm 30,8 \mathrm{pg} / \mathrm{ml}$ olarak tespit edildi. Oral tedavi grubunda ortalama B12 vitamini düzeyi 153,83 $\pm 31,24 \mathrm{pg} / \mathrm{ml}$ iken intramüsküler tedavi grubunda 156,17 $\pm 30,54 \mathrm{pg} / \mathrm{ml}$ olarak tespit edildi. $(p>0,05)$ Tedavi sonrası ortalama B12 vitamini düzeyi $375,18 \pm 24,43 \mathrm{pg} / \mathrm{ml}$ olarak tespit edildi. Oral tedavi grubunda tedavi sonrası kontrol B12 vitamini düzeyi $405,89 \pm 300,29 \mathrm{pg} / \mathrm{ml}$, intramüsküler tedavi grubunda ise $339,13 \pm 150,58 \mathrm{pg} / \mathrm{ml}$ olarak tespit edildi. Tüm hastalarda anlamlı B12 vitamini düzey yükselmesi sağlandığı tespit edildi $(p<0,001)$. Oral ve intramüsküler tedavi gruplarında meydana gelen B12 vitamini düzey artışları arasında anlamlı farklılık saptanmadı $(p>0,05)$. Tablo 3 hastaların başlangıç ve kontrol laboratuvar değerlerinin değişimlerini göstermektedir. Çalışmaya alınan hastaların $\% 92,15$ 'inde B12 vitamini düzeyinin normal aralığa geldiği
$\% 98,03$ hastada B12 vitamini düzeyinde artış olduğu görüldü. Bu oranlar oral tedavi grubunda sırasıyla $\% 91,07$ ve $\% 98,21$, intramüsküler tedavi grubunda sırasıyla $\% 93,47$ ve $\% 97,82$ olarak tespit edildi.

Tablo 2. Gruplara göre kronik hastalık dağılımları

\begin{tabular}{|c|c|c|c|c|c|c|}
\hline & \multicolumn{2}{|c|}{ Tüm vakalar } & \multirow{2}{*}{$\begin{array}{l}\begin{array}{l}\text { Oral } \\
\text { grubu }\end{array} \\
\text { Hasta } \\
\text { sayıs }\end{array}$} & \multirow{2}{*}{$\begin{array}{l}\text { tedavi } \\
\%\end{array}$} & \multicolumn{2}{|c|}{$\begin{array}{l}\text { Intramüsküler } \\
\text { tedavi grubu }\end{array}$} \\
\hline & $\begin{array}{l}\text { Hasta } \\
\text { sayıII }\end{array}$ & $\%$ & & & $\begin{array}{l}\text { Hasta } \\
\text { sayıII }\end{array}$ & $\%$ \\
\hline Hipotiroidi & 9 & 8,82 & 4 & 7,14 & 5 & 10,86 \\
\hline $\begin{array}{l}\text { Diabetes } \\
\text { Mellitus }\end{array}$ & 25 & 24,5 & 15 & 26,78 & 10 & 21,73 \\
\hline $\begin{array}{l}\text { Hipertansi- } \\
\text { yon } \\
\text { Gastrik / }\end{array}$ & 23 & 22,54 & 15 & 26,78 & 8 & 17,39 \\
\hline $\begin{array}{l}\text { Peptik } \\
\text { Ülser }\end{array}$ & 13 & 12,74 & 8 & 14,28 & 5 & 10,86 \\
\hline $\begin{array}{l}\text { Hiperlipi- } \\
\text { demi } \\
\text { Kronik }\end{array}$ & 9 & 8,82 & 8 & 14,28 & 1 & 2,17 \\
\hline $\begin{array}{l}\text { Böbrek } \\
\text { Hastalığı }\end{array}$ & 1 & 0,98 & 1 & 1,78 & 0 & 0 \\
\hline $\begin{array}{l}\text { Demir } \\
\text { Eksikliği }\end{array}$ & 15 & 15,68 & 7 & 12,5 & 8 & 17,39 \\
\hline Hipertirodi & 1 & 0,98 & 1 & 1,78 & 0 & 0 \\
\hline Psöriazis & 2 & 1,96 & 1 & 1,78 & 1 & 2,17 \\
\hline Malignite & 3 & 2,94 & 2 & 3,57 & 1 & 2,17 \\
\hline Trombofili & 1 & 0,98 & 1 & 1,78 & 0 & 0 \\
\hline Astım & 1 & 0,98 & 1 & 1,78 & 0 & 0 \\
\hline $\begin{array}{l}\text { Depresyon } \\
\text { Koroner }\end{array}$ & 2 & 1,96 & 0 & 0 & 2 & 4,34 \\
\hline $\begin{array}{l}\text { Arter } \\
\text { Hastalığı }\end{array}$ & 1 & 0,98 & 0 & 0 & 1 & 2,17 \\
\hline Veritgo & 1 & 0,98 & 0 & 0 & 1 & 2,17 \\
\hline $\begin{array}{l}\text { Behçet } \\
\text { Hastalığı } \\
\text { Kronik }\end{array}$ & 1 & 0,98 & 0 & 0 & 1 & 2,17 \\
\hline $\begin{array}{l}\text { Hastalık } \\
\text { Yok }\end{array}$ & 30 & 29,41 & 16 & 28,57 & 14 & 30,43 \\
\hline
\end{tabular}

B12 vitamini eksikliği ile yaş arasında korelasyon analizi yapıldığında yaş ile eksikliğin derinliğinde artma olduğu ancak tedavi cevabının yaş ile korelasyon göstermediği tespit edildi.

Metformin kullanan oral ve intramüsküler tedavi gruplarında bulunan hastalar B12 vitamini düzey artışı açısından karşılaştırıldığında oral tedavi grubunda ortanca B12 vitamini düzey artışı 109,5 pg/ml, intramüsküler tedavi grubunda $153 \mathrm{pg} / \mathrm{ml}$ olarak saptandı $(p>0,05)$.

Proton pompa inhibitörü kullanan oral ve intramüsküler tedavi kollarında bulunan hastalar B12 vitamini düzey artışı açısından karşılaştııılığında oral tedavi grubunda ortanca B12 vitamini düzey artışı 152,5 pg/ml, intramüsküler tedavi grubunda 171,3 pg/ml olarak saptandı $(p>0,05)$.

\section{Tartışma}

Multisistemik sorunlara yol açabilen B12 vitamini eksikliğinin toplumda görülme sıkılığının yüksek olmasının yanı sıra, yaşılların eksiklik gelişimi açısından daha riskli olduğu belirtilmektedir (23). Eksiklik sebepleri; gastrointestinal sebepler, diyet, ilaç etkileşimi ve herediter sebeplere bağlı 
gelişen eksiklikler olarak kabaca sınıflandıılabilir (20). Eksiklik gelişmesi durumunda sıklıkla intramüsküler enjeksiyon ile replasman tedavisi yapılmaktadır (18). Ancak bu tedavi için hastalar bir sağlık kuruluşuna başvurmak zorunda kalmakta ve intramüsküler enjeksiyonun riskleri ile karşı karşıya kalmaktadırlar $(17,18)$. Değişik sebeplerden ötürü hastalar intramüsküler tedavi uygulanabilecek merkeze ulaşımda zorluk yaşayabilmekte, bu durum tedavinin yapılmamasına veya eksik bırakılmasına sebep olabilmektedir (19). Bu sebeplerden nedeni ile oral replasman tedavisi gündeme gelmektedir.

Tablo 3. Hastaların başlangıç ve tedavi sonrası laboratuvar değerlerinin karşılaştııııması

\begin{tabular}{|c|c|c|c|c|c|c|c|c|c|}
\hline & \multicolumn{3}{|c|}{ Tüm vakalar (n=102) } & \multicolumn{3}{|c|}{$\begin{array}{l}\text { Oral tedavi grubu } \\
(n=56)\end{array}$} & \multicolumn{3}{|c|}{$\begin{array}{l}\text { İntramüsküler tedavi } \\
\text { grubu }(n=46)\end{array}$} \\
\hline & $\begin{array}{l}\text { Baş- } \\
\text { langıç }\end{array}$ & $\begin{array}{l}\begin{array}{l}\text { Kont- } \\
\text { rol }\end{array} \\
\end{array}$ & $\begin{array}{l}p \text { de- } \\
\text { ğeri }\end{array}$ & $\begin{array}{l}\text { Baş- } \\
\text { langıç }\end{array}$ & Kontrol & $\begin{array}{l}p \text { de- } \\
\text { ğeri }\end{array}$ & $\begin{array}{l}\text { Baş- } \\
\text { langıç }\end{array}$ & Kontrol & $\begin{array}{l}\mathrm{p} \text { de- } \\
\text { geri }\end{array}$ \\
\hline \multicolumn{10}{|l|}{ Beyaz } \\
\hline $\begin{array}{l}\text { Küre } \\
\text { SayıSı } \\
\text { (X1031 } \\
\text { mililitre) }\end{array}$ & $\begin{array}{l}7,49 \pm \\
2,11\end{array}$ & $\begin{array}{l}7,44 \pm \\
1,60\end{array}$ & $>0,05$ & $\begin{array}{l}7,44 \pm \\
1,95\end{array}$ & $\begin{array}{l}7,65 \\
\pm \\
1,49\end{array}$ & $>0,05$ & $\begin{array}{l}7,56 \pm \\
2,31\end{array}$ & $\begin{array}{l}7,25 \pm \\
1,71\end{array}$ & $>0,05$ \\
\hline $\begin{array}{l}\text { Hemog- } \\
\text { lobin } \\
\text { (gram/ } \\
\text { desilitre) }\end{array}$ & $\begin{array}{l}13,81 \\
\pm 1,76\end{array}$ & $\begin{array}{l}13,92 \\
\pm 1,45\end{array}$ & $>0,05$ & $\begin{array}{l}14,09 \\
\pm 1,57\end{array}$ & $\begin{array}{l}14,12 \pm \\
1,34\end{array}$ & $>0,05$ & $\begin{array}{l}13,47 \\
\pm 1,93\end{array}$ & $\begin{array}{l}13,71 \pm \\
1,55\end{array}$ & $>0,05$ \\
\hline $\begin{array}{l}\text { Orta- } \\
\text { lama } \\
\text { Eritrosit } \\
\text { volümü } \\
\text { (fl) }\end{array}$ & $\begin{array}{l}85,37 \\
\pm 6,25\end{array}$ & $\begin{array}{l}85,03 \\
\pm 4,43\end{array}$ & $>0,05$ & $\begin{array}{l}86,01 \\
\pm 5,51\end{array}$ & $\begin{array}{l}85,66 \pm \\
3,34\end{array}$ & $>0,05$ & $\begin{array}{l}84,58 \\
\pm 7,03\end{array}$ & $\begin{array}{l}84,29 \pm \\
5,33\end{array}$ & $>0,05$ \\
\hline $\begin{array}{l}\text { Platelet } \\
\text { sayıSI } \\
\text { (X1031 } \\
\text { mililitre) }\end{array}$ & $\begin{array}{l}275 \pm \\
71\end{array}$ & $\begin{array}{l}279 \pm \\
62\end{array}$ & $>0,05$ & $\begin{array}{l}271 \pm \\
76\end{array}$ & $282 \pm 63$ & $>0,05$ & $\begin{array}{l}279 \\
\pm \\
64\end{array}$ & $276 \pm 61$ & $>0,05$ \\
\hline $\begin{array}{l}\text { LDH } \\
\text { (ünitel } \\
\text { litre) }\end{array}$ & $\begin{array}{l}298,87 \\
\pm \\
67,92\end{array}$ & $\begin{array}{l}277,50 \\
\pm \\
75,69\end{array}$ & $>0,05$ & $\begin{array}{l}302,7 \\
6 \pm \\
63,64\end{array}$ & $\begin{array}{l}270,58 \\
\pm 70,24\end{array}$ & $>0,05$ & $\begin{array}{l}291,9 \\
6 \\
\pm \\
75,52\end{array}$ & $\begin{array}{l}289 \pm \\
86,32\end{array}$ & $>0,05$ \\
\hline $\begin{array}{l}\text { B12 Vi- } \\
\text { tamin } \\
\text { düzeyi } \\
\text { (pikog- } \\
\text { ram/ } \\
\text { mililitre) }\end{array}$ & $\begin{array}{l}154,88 \\
\pm \\
30,80\end{array}$ & $\begin{array}{l}375,18 \\
\pm \\
24,43\end{array}$ & $\begin{array}{l}<0,00 \\
1\end{array}$ & $\begin{array}{l}153,8 \\
3 \quad \pm \\
31,24\end{array}$ & $\begin{array}{l}405,89 \\
\pm \\
300,29\end{array}$ & $\begin{array}{l}<0,00 \\
1\end{array}$ & $\begin{array}{l}156,1 \\
7 \quad \pm \\
30,54\end{array}$ & $\begin{array}{l}339,13 \\
\pm \\
150,58\end{array}$ & $\begin{array}{l}<0,00 \\
1\end{array}$ \\
\hline
\end{tabular}

$2000 \mu g / g u ̈ n$ oral vitamini B12 replasmanı ile intramüsküler replasmana göre daha yüksek B12 vitamini kan düzeyi artışı sağlanabilmekte ve hematolojik ve nörolojik parametrelerde düzelme sağlanmaktadır (11). Bu yüzden oral alıma engel durumu olmayan hastalarda oral yol ile B12 vitamini replasmanı yapılabilmekte (24); ancak megaloblastik anemisi olan hastalarda oral replasman tedavisi ile yanıt daha yavaş olabilmektedir (25). Hastalarda 50 ila $2000 \mu \mathrm{g} / g u ̈ n$ aralığında değişen dozlarla uygulanan oral B12 replasmanı ile plaseboya göre anlamlı düzey artışı sağlanabilmektedir (25). Buna karşın, hangi doz ile ne kadar süre tedavi verileceği ile ilgili net veri bulunmamaktadır. Yaptığımız bu çalışmada \%92,15 hastada B12 vitamini düzeyinin replasman tedavisi ile normal aralığa geldiği, \% 98,03 hastada B12 vitamini düzeyinde artış olduğunu tespit etmemiz daha önce yapılan oral B12 vitamini replasmanı çalışmaları ile uyumlu olarak yorumlanabilir. Ilioplasti yapılan hastalarda oral vitamini B12 replasmanı ile geç dönemde bile olsa anlamlı B12 yüksekliği saptanabilmesi ve pernisyöz anemili hastalarda $250 \mu \mathrm{g} / g u ̈ n$ oral vitamini B12 replasman dozu ile 1 ay sonunda tüm hastalarda B12 vitamini düzeyinde artış olması, B12 vitamininin intestinal emilimi için bilinen klasik intrinsik faktör yolağı dışında yolaklar olabileceğini akla getirmekte ve bu yolaklar sayesinde oral tedavinin eksiklik durumunda kullanılabileceği sonucunun ortaya çıkmasına sebep olmaktadır $(23,26)$. Yaptığımız çaIışmada B12 eksiklik düzey düşüklüğünden bağımsız olarak oral vitamini B12 replasmanı ile hastalarda başlangıç B12 vitamin düzeylerine göre anlamlı yükselme sağlanması litaratürde var olan çalışmalar ile benzerdir.

Metformin kullanan hastalarda B12 vitamini eksikliği gelişme riski \%22-29 aralığındadır $(22,27)$. Sublingual ve intramüsküler B12 replasman tedavisi metformin kullanan tip 2 diyabetli hastalarda tedavide kullanılabilir (22). Benzer şekilde çalışmamızda metformin kullanan hastalarda oral ve intramüsküler replasman tedavisi ile benzer B12 vitamini düzey artışı sağlanmıştır. Ancak intramüsküler tedavi ile istatistiksel olarak fark olmasa bile, daha fazla düzey artışı olması, kalsiyum aracılı B12 vitamini emilimini bozduğu bilinen metformini kullanan hastalarda, oral replasman dozu ve süresi ile ilgili yeni kontrollü çalışmaların yapıımasının gerekliliğini ortaya koymaktadır.

B12 vitaminin mide asidi etkisi ile besinlerden serbestleşmesinde azalmaya yol açabilen ve özellikle yaşıllarda bakteriyel aşırı çoğalamaya bağlı olarak B12 vitamini eksikliğine sebep olabilen proton pompa inhibitörü kullanımı olan hastalarda oral vitamin B12 replasmanı ile ilgili yeterli veri bulunmamaktadır. Ancak bu çalışmada az vaka sayısına rağmen oral B12 replasmanı ile sağlanan 152,5 pg/ml B12 vitamini düzey artışı proton pompa inhibitörü kullanan hastalarda oral tedavinin akla getirilebileceği sonucu yaratmaktadır. Konu ile ilgili yeni çalışmalara ihtiyaç vardır.

Etyoloji ne olursa olsun oral vitamin B12 replasmanı ile hematolojik ve nörolojik iyileşme sağlanabilmektedir (18). Bu çalışma ile de $1000 \mu \mathrm{g} /$ gün oral vitamin B12 replasman tedavisi ile benzer sonuçlara ulaşılmış olsa bile, bu çalı̧̧mada hastaların sadece vitamin B12 kan düzeylerinin düşük olması, hematolojik tutulum görülmemiş olması $(5,13)$, retrospektif yapısından dolayı nörolojik defisit varlığının ve hastaların tedavi uyumlarının değerlendirilememesi, eksikliğin homosistein ve metil malonik asit bakılarak doğrulanmamış olması, uzun dönem takip ile ilgili verilerin olmaması çalışmanın sınırlııklarını oluşturmakta ve oral tedavi B12 vitamini eksikliği tespit edilen hastalarda intramüsküler tedavinin alternatifidir sonucuna ulaşmayı engellemektedir.

Sonuç olarak, toplumda sık görülen ve yaş ile görülme sıklığı artan, tedavi edilmediği durumda ciddi hematolojik, nörolojik ve kognitif bozukluklara yol açan B12 vitamini eksikliğinin tedavisinde oral replasman tedavisinin kullanılabile- 
ceği düşünülmektedir. Ancak doz, replasman süresi, verilebilecek hasta gruplarının tanımlanacağı, daha geniş kapsamlı, kontrollü klinik çalışmalara intiyaç vardır.

Etik Onam: Ankara Numune Eğitim Araştırma Hastanesi (ANEAH) Bilimsel Araştırmalar Değerlendirme Komisyonunun 24/07/2013 tarih ve 2013 - 646 sayılı kararı

\section{Kaynaklar}

1. Green R, Kinsella LJ. Current concepts in the diagnosis of cobalamin deficiency. Neurology. 1995;45(8):1435-1440.

2. Sullivan LW, Herberty V. Studies on the minimal daily requirement for vitamin B12 hematopoietic responses to 0.1 micrograms of cyanocobalamin or coenzyme B12 and comparison of their reletive potency. $\mathrm{N}$ Engl J Med. 1965;272:340-346.

3. Tefferi A, Pruthi RK. The biochemical basis of cobalamin deficiency. Mayo Clin Proc. 1994; 69(2):181-186.

4. Allen RH, Stabler SP, Savage DG, Lindenbaum J. Metabolic abnormalities in cobalamin (vitamin B12) and folate deficiency. FASEB J. 1993; 7(14):1344-1353.

5. Pruthi RK, Tefferi A. Pernicious anemia revisited. Mayo Clin Proc. 1994;69(2):144-150.

6.Toh BH, van Driel IR, Gleeson PA. Pernicious anemia. N Engl J Med. 1997;337(20):1441-1448.

7.Carmel R. How I treat cobalamin (vitamin B12) deficiency. Blood. 2008;112(6):2214-2221.

8. Andrès $E$, Goichot $B$, Schlienger JL. Food cobalamin malabsorption: a usual cause of vitamin B12 deficiency. Arch Intern Med. 2000;160(13):2061-2062.

9. Andrès $\mathrm{E}$, Loukili NH, Noel E, Kaltenbach G, Abdelgheni MB, Perrin $\mathrm{AE}$, et al. Vitamin B12 (cobalamin) deficiency in elderly patients. CMAJ. 2004;171(3):251-259.

10. Dali-Youcef $N$, Andrès $E$. An update on cobalamin deficiency in adults. QJM. 2009;102(1):17-28.

11. Lindenbaum J, Healton EB, Savage DG, Brust JC, Garrett TJ, Podell $E R$, et al. Neuropsychiatric disorders caused by cobalamin deficiency in the absence of anemia or macrocytosis. N.Engl $\mathrm{J}$ Med. 1988;318(26):1720-1728.

12. Hemmer B, Glocker FX, Schumacher M, Deuschl L, Lücking CH. Subacute combined degeneration: clinical, electrophysiological, and magnetic resonance imaging findings. Neurol Neurosurg Psychiatry. 1998;65(6):822-827.

13. Dhonukshe-Rutten RA, Lips $M$, de Jong N, Chin A Paw M, Hiddink $G$, van Dusseldorp M, et al. Vitamin B-12 status is associated with bone mineral content and bone mineral density in frail elderly women but not in men. J Nutr. 2003; 133(3):801-807.

14. Savage DG, Lindenbaum J, Stabler SP, Allen RH. Sensitivity of serum methylmalonic acid and total homocysteine determinations for diagnosing cobalamin and folate deficiencies. Am J Med. 1994;96(3):239246.

15. Lindenbaum J, Savage DG, Stabler SP, Allen RH. Diagnosis of cobalamin deficiency: II. Relative sensitivities of serum cobalamin, methylmalonic acid and total homocysteine concentrations. Am J Hematol. 1990;34(2):99-107.

16. Matchar DB, McCrory DC, Millington DS, Feussner JR. Performance of the serum cobalamin assay for diagnosis of cobalamin deficiency. Am J Med Sci. 1994;308(5):276-283.

17. Stabler SP. Clinical Practice.Vitamin B12 deficiency. N Engl J Med 2013;368(2):149-160.

18. Green R. Screening for vitamin B12 deficiency: caveat emptor. Ann Intern Med. 1996;124(5):509-511.

19. Stabler SP, Allen RH, Savage DG, Lindenbaum J. Clinical spectrum and diagnosis of cobalamin deficiency. Blood. 1990;76(5):871-881.

20. Solomon LR. Cobalamin-responsive disorders in the ambulatory care setting: unreliability of cobalamin, methylmalonic acid, and homocysteine testing. Blood. 2005;105(3):978-1137.

21. Hvas AM, Ellegaard J, Nexø E. Increased plasma methylmalonic acid level does not predict clinical manifestations of vitamin B12 deficiency. Arch Intern Med. 2001;161(12):1534-1541.

22. Hathcock JN, Troendle GJ. Oral cobalamin for treatment of pernicious anemia?. JAMA. 1991;265(1):96-97.

23. Solomon LR. Oral vitamin B12 therapy: cautionary note. Blood. 2004;103(7):2863.

24. Eussen SJ, de Groot LC, Clarke R, Schneede J, Ueland PM, Hoafnagels $\mathrm{W}$, et al. Oral cyanocobalamin supplementation in older people with vitamin B12 deficiency: a dose-finding trial. Arch Intern Med. 2005;165(10):1167-1172.

25. Kuzminski AM, Del Giacco EJ. Allen RH, Stabler SP, Lindenbaum J. Effective treatment of cobalamin deficiency with oral cobalamin. Blood. 1998;92(4):1191-1198.

26. Butler CC, Vidal-Alaball J, Cannings-John R, McCaddon A, Hood $K$, Papaioannou $A$, et al. Oral vitamin $B 12$ versus intramuscular vitamin B12 for vitamin B12 deficiency: a systematic review of randomized controlled trials. Family Practice. 2006;23(3):279-285.

27. Delpre G, Stark P, Niv Y. Sublingual therapy for cobalamin deficiency as an alternative to oral and parenteral cobalamin supplementation. Lancet. 1999;354(9180):740-741.

28. Slot WB, Merkus FW, Van Deventer SJ, Tytgat GN. Normalization of plasma vitamin B12 concentration by intranasal hydroxocobalamin in vitamin B12-deficient patients. Gastroenterology. 1997;113(2):430-433. 29. Kondo H. Haematological effects of oral cobalamin preparations on patients with megaloblastic anaemia. Acta Haematol. 1998;99:200-205 30. Nyholm E, Turpin P, Swain D, Cunningham B, Daly S, Nightingale $\mathrm{P}$, et al. Oral vitamin B12 can change our practice. Postgrad Med J. 2003;79:218-220.

31. Favrat B, Vaucher P, Herzig L, Burnand B, Ali G, Boulat O, et al. Oral vitamin B12 for patients suspected of subtle cobalamin deficiency: a multicentre pragmatic randomised controlled trial. BMJ Family Practice. 2011;12:2

32. Brian A,VanderBrink BA, Cain MP, King S, Meldrum K, et al. İs oral vtamin B12 therapy effective for vitamin B12 deficiency in patients with plior ileocystoplasty?. The Journal Of Urology. 2010;184(4S):17811785.

33. Andres A, Kaltenbach G, Noel E, Noblet-Dick M, Vogel T, et al. Efficacy of short-term oral cobalamin therapy for the treatment of cobalamin deficiencies related to food- cobalamin malabsorption: A study of 30 patients. Clin. Lab. Haem. 2003;25(3):161-166

34. Verhaeverbeke I, Mets T, Mulkens K, Vandewoude M. Normalization of low vitamin B12 serum levels in older people by oral treatment. J Am Geriatr Soc. 1997;45(1):124-125.

35. DeFronzo R, Goodman A. Efficacy of metformin in patients with noninsülin dependent diabetes mellitus The Multicenter Metformin Study Group. N Eng J Med. 1995;333(9):541-549.

36. De-Jager J, Kooy A, Lehert P, Wulffele MG, van der Kolk J, Bets D, et al. Long term treatment with metformin in patients with type 2 diabetes and risk of vitamin B-12 deficiency:randomised placebo controlled trial. BMJ. 2010;340:c2181.

37. Ting R, Szeto C. Chan M, Ma K, Chow K. Risk factors of vitamin B12 deficiency in patients receiving metformin. Arch Intern Med. 2006;166(18):1975-1979.

38. Parry-Strong A, Langdana F, Haeusler S, Weatherall M, Krebs J. Sublingual vitamin B12 compared to intramuscular injection in patients with type 2 diabetes treated with metformin: a randomised trial. N Z Med J. 2016;129(1436):67-75 